\title{
Fatal infection with emerging apicomplexan parasite Hepatozoon silvestris in a domestic cat
}

\author{
Kristel Kegler ${ }^{1}$, Ursina Nufer ${ }^{2}$, Amer Alic $^{3}$, Horst Posthaus ${ }^{1}$, Philipp Olias ${ }^{1 *+}$ (D) and Walter Basso ${ }^{4 \dagger}$
}

\begin{abstract}
Background: Hepatozoon silvestris is an emerging apicomplexan parasite discovered in European wild cats from Bosnia and Herzegovina and blood samples of a domestic cat from Southern Italy in 2017. It has also been identified in Ixodes ricinus collected from a domestic cat in Wales, UK, in 2018. The clinical relevance, pathogenesis and epidemiology of this novel Hepatozoon species are not yet understood. Thus, the objective of this paper was to report and describe the first fatal case of an $\mathrm{H}$. silvestris infection in a domestic cat.

Results: The cat, which originated from Switzerland, died shortly after presenting clinical signs of lethargy, weakness and anorexia. At necropsy, no specific lesions were observed. Histopathology of the heart revealed a severe lympho-plasmacytic and histiocytic myocarditis. Mature and developing protozoal meronts morphologically compatible with Hepatozoon species were observed associated with the myocardial inflammation. No other lesions were present in any other organ evaluated, and the cat tested negative for retroviral and other immunosuppressive infectious agents. Polymerase chain reaction from the myocardium resulted in a specific amplicon of the Hepatozoon 185 rRNA gene. Sequencing and BLAST analysis revealed 100\% sequence identity with $H$. silvestris.

Conclusions: The severity of the infection with fatal outcome in an otherwise healthy animal suggests a high virulence of $\mathrm{H}$. silvestris for domestic cats. The presence of this emerging parasite in a domestic cat in Switzerland with no travel history provides further evidence for a geographical distribution throughout Europe.
\end{abstract}

Keywords: Domestic cat, Myocarditis, Hepatozoon silvestris, Apicomplexa, Switzerland

\section{Background}

Hepatozoon species are apicomplexan parasites (family Hepatozoidae) with more than 340 species recognized $[1,2]$. Unlike most vector-borne protozoan pathogens which are transmitted during a blood meal, Hepatozoon infections take place when the intermediate vertebrate host ingests the definitive host, an invertebrate, containing mature oocysts [3]. Other modes of transmission, such as transplacental or by predation of infected intermediate hosts, have been reported [4-6]. Recent studies involving molecular diagnostic techniques identified two distinct species, $H$. americanum and $H$. canis, infecting wild and domestic carnivores [7-11], while $H$. felis was

\footnotetext{
* Correspondence: philipp.olias@vetsuisse.unibe.ch

†Philipp Olias and Walter Basso contributed equally to this work.

'Institute of Animal Pathology, Vetsuisse Faculty, University of Bern, Bern,

Switzerland

Full list of author information is available at the end of the article
}

recognized in wild and domestic felids [6, 10, 12, 13]. Studies on domestic cats from European countries including Italy [14], France [15], Spain [16] and Portugal [17] identified H. felis in blood samples. In 2017, Hepatozoon silvestris was described as novel species in European wild cats (Felis silvestris silvestris) from Bosnia and Herzegovina [13]. Shortly thereafter, H. silvestris DNA was amplified and sequenced from blood samples of a domestic cat from southern Italy [14] and Ixodes ricinus ticks collected from a domestic cat in Wales, UK [18].

The pathogenic potential of feline hepatozoonosis in general is poorly understood. Hepatozoon felis infection in domestic cats is considered subclinical with no apparent inflammatory response associated with the presence of meronts in muscle tissue $[2,6,8,16,19]$. Similar to $H$. felis, $H$. silvestris infects myocardial and skeletal muscles in European wild cats and has been found to be associated with only a minimal inflammatory response

(c) The Author(s). 2018 Open Access This article is distributed under the terms of the Creative Commons Attribution 4.0 International License (http://creativecommons.org/licenses/by/4.0/), which permits unrestricted use, distribution, and 
[13]. Here we report the first fatal case of $H$. silvestris infection associated with a severe myocarditis in a domestic cat.

\section{Methods}

At necropsy, representative samples of the heart, lung, liver, kidneys, spleen, lymph nodes, bone marrow, stomach, intestine and brain were collected, fixed in 10\% neutral buffered formalin, processed routinely and embedded in paraffin wax. Sections of $3 \mu \mathrm{m}$ were stained with haematoxylin and eosin (HE). Polymerase chain reaction (PCR) to identify Hepatozoon species was performed using the primers H14Hepa18SFw and H14Hepa18SRv [20], which amplify a fragment of the $18 \mathrm{~S}$ rRNA gene of Hepatozoon spp. For this, DNA was extracted from $20 \mu \mathrm{m} \mathrm{sec-}$ tions of formalin-fixed and paraffin-embedded (FFPE) tissue of the heart as previously described [21]. As a positive control, DNA extracted from FFPE heart sections of a naturally infected European wild cat [13] was used. DNA amplification was conducted under the following conditions: $95{ }^{\circ} \mathrm{C}$ for $15 \mathrm{~min}$, followed by 35 cycles at $58^{\circ} \mathrm{C}$ for $1 \mathrm{~min}, 72^{\circ} \mathrm{C}$ for $1 \mathrm{~min}$ and $95^{\circ} \mathrm{C}$ for $1 \mathrm{~min}$, and a final extension at $72{ }^{\circ} \mathrm{C}$ for $5 \mathrm{~min}$. The amplified PCR product was purified using a commercial kit (DNA Clean \& Concentrator-5 Zymo Research, Irvine, USA) and subsequently sequenced (Microsynth, Balgach, Switzerland) in both directions with the same primers as used in the PCR. An additional real time PCR targeting the Toxoplasma gondii B1 gene was carried out as previously described [22]. Alignment of the sequence of Hepatozoon species was performed using CLUSTALW incorporated in the MEGA7 software package [23]. Unrooted phylogenetic networks were generated with SplitsTree4 (v. 4.14 .6 [24]) using a neighbor-net method. jModelTest2 [25] identified $\mathrm{HKY}+\mathrm{I}$ as optimal substitution model.

\section{Results}

A 5-year-old neutered male European shorthair cat from the municipality of Hofstetten bei Brienz (approximate location: $46^{\circ} 45^{\prime} 17^{\prime \prime} \mathrm{N} 8^{\circ} 4^{\prime} 38^{\prime \prime} \mathrm{E}$ ) was presented to a private veterinary clinic in Meiringen, Switzerland in September 2017 with clinical signs of lethargy, weakness and anorexia. At clinical examination no ectoparasites were observed. The cat had free outdoor access, never traveled to another country, and was regularly dewormed, and vaccinated against feline panleukopenia, feline viral rhinotracheitis and feline calicivirus (FCV). Blood samples were collected and sent to a private laboratory for hematologic and biochemical analyses, and feline immunodeficiency virus (FIV) and feline leukemia virus (FeLV) testing. The cat received intravenous infusions but died shortly after admission and was sent to the Institute of Veterinary Pathology of the Vetsuisse Faculty in Bern, Switzerland for complete post mortem evaluation. Hematologic and biochemical analysis of blood samples revealed mild thrombocytopenia $(159 \mathrm{~K} / \mu \mathrm{l}$; reference range $175-600 \mathrm{~K} /$ $\mu \mathrm{l})$ and slightly increased pancreatic lipase enzyme (1446 U/l; reference range 100-1400 U/l). Red blood cell (RBC) and white blood cell (WBC) count, as well as standard biochemical parameters were within normal range. Additionally, blood samples tested negative for FIV and FeLV. At necropsy, the animal was in a good nutritional state. Gross lesions were unspecific and consisted of a mild generalized lymphadenomegaly, presence of approximately 10 $\mathrm{ml}$ of serous transudate within the thoracic cavity, mild pulmonary edema, and mild diffuse myocardial pallor of both ventricles of the heart.

Histopathology of the heart disclosed a severe multifocal to coalescing lympho-plasmacytic and histocytic myocarditis associated with cardiomyocyte degeneration and necrosis, few neutrophils, moderate interstitial edema and multifocal hemorrhages (Fig. 1a). Myocardial lesions were disseminated throughout both ventricles, the interventricular septum and the atria. The epicardium and endocardium were moderately and diffusely expanded by the same inflammatory infiltrate and marked edema. Protozoal meronts measuring up to $32 \times 22 \mu \mathrm{m}$ and enveloped by an up to $1 \mu \mathrm{m}$ thick capsule were associated with the inflammatory lesions (Fig. 1a, arrow). Mature and two different types of developing meronts were observed. Mature meronts (Fig. 1b) were characterized by numerous, round, $2-4 \mu \mathrm{m}$ in diameter irregularly scattered merozoites. The first type of developing meront contained approximately 20-30 small, up to $4 \times 2 \mu \mathrm{m}$, oval micromerozoites which were circularly arranged alongside the meront wall (Fig. 1c). The second type contained 2-8 larger and elongated macromerozoites, up to $6 \times 3 \mu \mathrm{m}$, which were dispersed within the meront or circularly arranged alongside the meront wall (Fig. 1d). Additional findings included moderate pulmonary alveolar histiocytosis and interstitial edema, acute centrilobular hepatocellular degeneration and mild hepatic extramedullary hematopoiesis. Mild follicular hyperplasia was noted in tracheobronchial and mesenteric lymph nodes. No histopathological lesions were observed in the spleen, pancreas, kidneys, stomach, small and large intestines, brain and bone marrow.

Based on the presence of intralesional meronts in the heart muscle, the preliminary diagnosis of hepatozoonosis was made. Hepatozoon spp. DNA was amplified from the heart with genus specific primers. A PCR for $T$. gondii gave negative results. BLAST analysis and comparison of amplified 572 bp (GenBank: MH078194) with publically available sequences disclosed $100 \%$ sequence identity with H. silvestris from European wild cats (KX757032) and a feline blood sample from Italy (KY649445). The sequence similarity to the closest $H$. felis genotype (JN123435) was $96 \%$. The results of the phylogenetic analysis showed a close but distant relationship of $H$. silvestris 


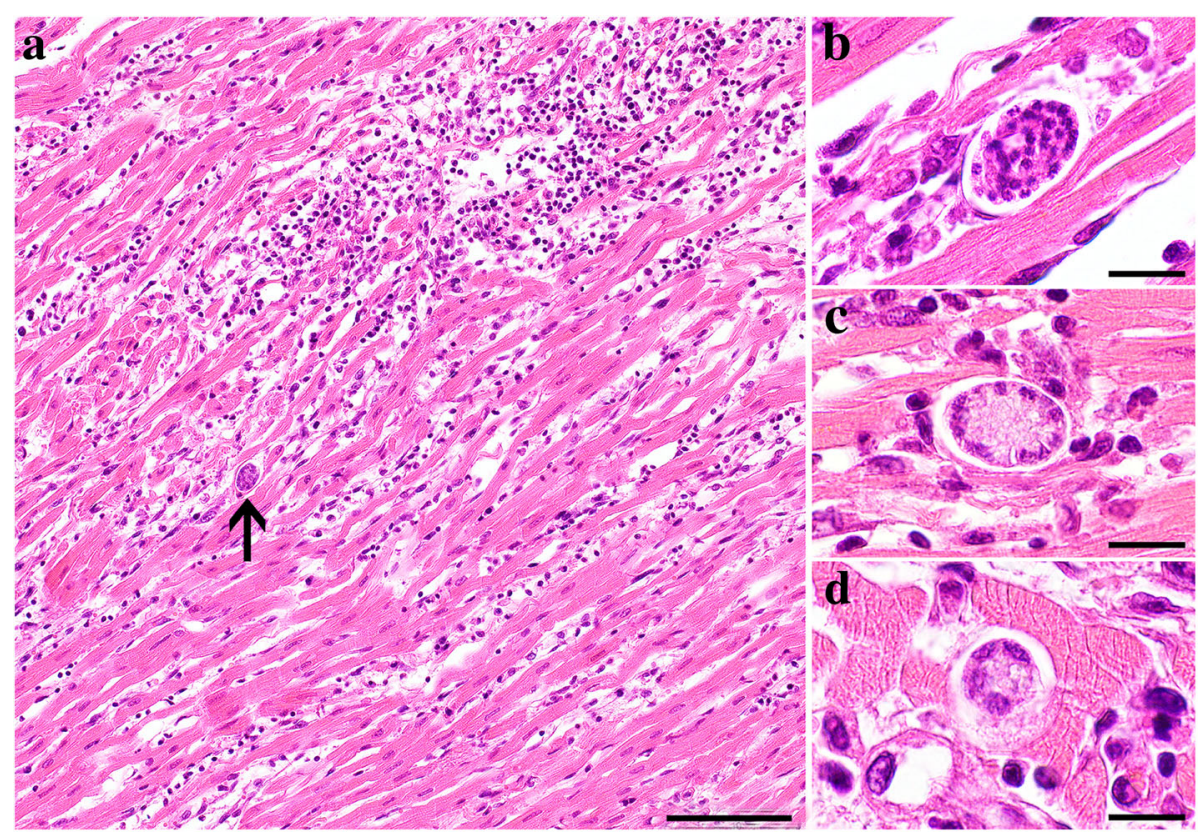

Fig. 1 Photomicrographs of the myocardium of the domestic cat infected with H. silvestris. a HE stained section of the myocardium severely infiltrated by lymphocytes, plasma cells and macrophages, with associated myofiber degeneration and necrosis. Note the presence of an intralesional mature meront (arrow). b Higher magnification of a mature meront filled with numerous merozoites. c Developing wheel-spoke shaped meront with micromerozoites arranged in a circle along the wall. d Developing meront with elongated circularly aligned macromerozoites. Scale-bars: a, $100 \mu$ m; b-d, $20 \mu \mathrm{m}$

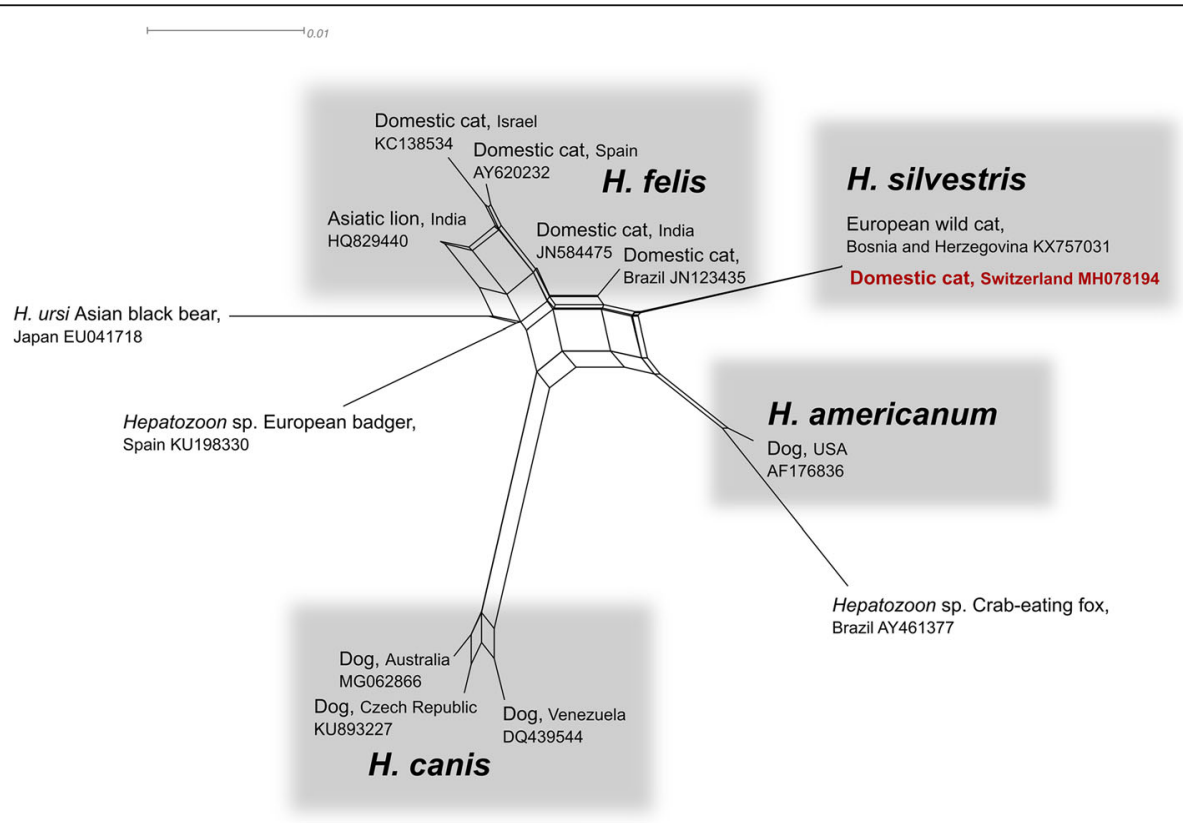

Fig. 2 Phylogenetic network of a trimmed 546 bp fragment of the 185 rRNA gene of Hepatozoon spp. as calculated by the neighbor-net algorithm in SplitsTree4. Hepatozoon silvestris and other species infecting domestic carnivores are shaded in grey. Note that the Hepatozoon $18 \mathrm{~S}$ sequence fragment derived from the infected myocardium of the domestic cat described here is identical to the sequence from a European wild cat from Bosnia-Herzegovina 
to multiple $H$. felis genotypes incorporated in the network calculation (Fig. 2).

\section{Discussion}

To our knowledge, this is the first report of a fatal myocarditis associated with the emerging parasite $H$. silvestris in a domestic cat. So far, epidemiological data on $H$. silvestris were limited to European wild cats from Bosnia and Herzegovina $[13,20]$ and a report of a positive feline blood sample from southern Italy [14]. Hepatozoon felis was considered the most common species infecting wild and domestic felids worldwide [6, 14, 16, 26-28]. In Europe, infections of cats with $H$. felis mainly occur in Mediterranean countries where hematophagous arthropods are more abundant $[8,12,14,16]$. The autochthonous case of an $H$. silvestris infection in Switzerland described here expands the geographical range of this emerging parasite.

The life-cycle and mode of transmission of feline hepatozoonosis is unknown. Recent studies were unable to establish a correlation between the infestation with arthropods and $H$. felis infection $[8,16]$. It is also noteworthy that haemolymph smears of ticks collected from $H$. silvestris infected European wild cats failed to demonstrate the presence of Hepatozoon oocysts [13]. In contrast, I. ricinus collected from a domestic cat in Wales, UK, in 2018 tested positive for $H$. silvestris PCR analysis [18]. It is therefore tempting to speculate that I. ricinus plays a role in the transmission of $H$. silvestris, potentially in addition to a transmission route by the ingestion of infected prey $[5,13]$. Epidemiological studies are needed to identify further invertebrate or vertebrate hosts involved in the life-cycle of this parasite.

The inflammatory lesions associated with $H$. silvestris reported here caused fatal heart failure in the domestic cat. The pulmonary and hepatic lesions most likely resulted from an acute cardiac insufficiency due to the myocardial lesions. Interestingly, the inflammatory response associated with $H$. silvestris meronts in the myocardium of European wild cats was very mild [13]. The closest relative, $H$. felis, is considered of low virulence and associated mostly with subclinical or mild clinical signs such as lethargy, fever, weakness and lymphadenopathy, and inconsistent blood and biochemical abnormalities $[6,8,16,19]$. Elevated levels of muscular activity enzymes including serum lactate dehydrogenase (LDH) and creatine phosphokinase $(\mathrm{CK})$ are described in a small number of cats infected with $H$. felis [8]. In the present case, the activity of muscular enzymes was not evaluated. Since PCR is widely used to detect $H$. felis in blood samples of apparently healthy domestic cats, further studies are needed to assess this less invasive method, together with a muscular enzymatic activity profile, as diagnostic tool in clinical cases of $H$. silvestris infection.
Immunosuppressive co-infections have been proposed to contribute to the severity of feline hepatozoonosis $[8,19,29]$. The cat presented here tested negative for feline immunocompromising retroviruses (FeLV and FIV) of cats and no lesions suggestive of any other concurrent immunosuppressive disease or infection were diagnosed. Our findings therefore strongly suggest that $H$. silvestris can cause fatal infections in otherwise healthy domestic cats.

\section{Conclusions}

The case of a H. silvestris infection in a domestic cat reported here demonstrates the presence of this emerging apicomplexan parasite in Switzerland. More importantly, the parasite-associated fatal myocarditis suggests a high virulence of $H$. silvestris for domestic cats [13]. Further epidemiological and experimental studies are needed to identify transmission routes, reservoir, definitive hosts and to elucidate the pathogenicity of this newly identified pathogen.

\section{Abbreviations}

DNA: deoxyribonucleic acid; FFPE: formalin-fixed and paraffin-embedded tissue; PCR: polymerase chain reaction; FCV: feline calicivirus; FIV: feline immunodeficiency virus; FeLV: feline leukemia virus; RBC: red blood cell; WBC: white blood cell; LDH: lactate dehydrogenase; CK: creatine phosphokinase

\section{Acknowledgements \\ The authors would like to thank Norbert Müller and Kemal Mehinagic for scientific assistance and Manuela Bozzo and Erika Burgi for technical support. \\ Funding \\ This case report was funded by the Institute of Animal Pathology and Institute of Parasitology of the Vetsuisse Faculty, University of Bern, Switzerland. PO is supported by the Swiss National Science Foundation (Ambizione PZOOP3_173972).}

\section{Availability of data and materials}

The dataset supporting the conclusions of this article are included within the article. Representative sequence was submitted to the GenBank database under the accession number MH078194.

\section{Authors' contributions}

$\mathrm{KK}$ and HP received the case from UN, performed the necropsy and histopathological evaluation. WB performed the DNA extraction and PCR analysis. AA provided positive controls of Hepatozoon silvestris and helped in PCR establishment. PO performed the phylogenetic analysis. KK and PO designed the study and wrote the manuscript with input from all authors. All authors read and approved the final manuscript.

\section{Ethics approval and consent to participate}

Not applicable.

\section{Consent for publication}

Not applicable.

\section{Competing interests}

The authors declare that they have no competing interests.

\section{Publisher's Note}

Springer Nature remains neutral with regard to jurisdictional claims in published maps and institutional affiliations. 


\section{Author details}

'Institute of Animal Pathology, Vetsuisse Faculty, University of Bern, Bern, Switzerland. ${ }^{2}$ Private Veterinary Clinic Dr. Usina Nufer, Meiringen, Switzerland. ${ }^{3}$ Department of Pathology, Faculty of Veterinary Medicine, University of Sarajevo, Sarajevo, Bosnia and Herzegovina. ${ }^{4}$ Institute of Parasitology, Vetsuisse Faculty, University of Bern, Bern, Switzerland.

Received: 22 April 2018 Accepted: 3 July 2018

Published online: 20 July 2018

\section{References}

1. Smith TG. The genus Hepatozoon (Apicomplexa: Adeleina). J Parasitol. 1996; 82:565-85.

2. Baneth G, Barta JR, Shkap V, Martin DS, Macintire DK, Vincent-Johnson N Genetic and antigenic evidence supports the separation of Hepatozoon canis and Hepatozoon americanum at the species level. J Clin Microbiol. 2000;38:1298-301.

3. Baneth G, Samish M, Shkap V. Life cycle of Hepatozoon canis (Apicomplexa: Adeleorina: Hepatozoidae) in the tick Rhipicephalus sanguineus and domestic dog (Canis familiaris). J Parasitol. 2007;93:283-99.

4. Murata T, Inoue M, Tateyama S, Taura Y, Nakama S. Vertical transmission of Hepatozoon canis in dogs. J Vet Med Sci. 1993;55:867-8.

5. Johnson EM, Panciera RJ, Allen KE, Sheets ME, Beal JD, Ewing SA, Little SE. Alternate pathway of infection with Hepatozoon americanum and the epidemiologic importance of predation. J Vet Intern Med. 2009;23:1315-8.

6. Baneth G, Sheiner A, Eyal O, Hahn S, Beaufils JP, Anug Y, Talmi-Frank D. Redescription of Hepatozoon felis (Apicomplexa: Hepatozoidae) based on phylogenetic analysis, tissue and blood form morphology, and possible transplacental transmission. Parasit Vectors. 2013;6:102.

7. Vincent-Johnson NA, Macintire DK, Lindsay DS, Lenz SD, Baneth G, Shkap V, Blagburn BL. A new Hepatozoon species from dogs: description of the causative agent of canine hepatozoonosis in North America. J Parasitol. 1997;83:1165-72

8. Baneth G, Aroch I, Tal N, Harrus S. Hepatozoons species infection in domestic cats: a retrospective study. Vet Parasitol. 1998;79:123-33.

9. Mathew JS, Van Den Bussche RA, Ewing SA, Malayer JR, Latha BR, Panciera RJ. Phylogenetic relationships of Hepatozoon (Apicomplexa: Adeleorina) based on molecular, morphologic, and life cycle characters. J Parasitol. 2000; 86:366-72.

10. Pawar RM, Poornachandar A, Srinivas P, Rao KR, Lakshmikantan U, Shivaji S. Molecular characterization of Hepatozoon spp. infection in endangered Indian wild felids and canids. Vet Parasitol. 2012;186:475-9.

11. Najm NA, Meyer-Kayser E, Hoffmann L, Pfister K, Silaghi C. Hepatozooncanis in German red foxes (Vulpes vulpes) and their ticks: molecular characterization and the phylogenetic relationship to other Hepatozoon spp. J Parasitol Res. 2014;113:2679-85.

12. Ortuño A, Castellà J, Criado-Fornelio A, Buling A, Barba-Carretero JC. Molecular detection of a Hepatozoon species in stray cats from a feline colony in north-eastern Spain. Vet J. 2008;177:134-5.

13. Hodžić A, Alić A, Prašović S, Otranto D, BanethG, Duscher GG. Hepatozoon silvestris sp. nov.: morphological and molecular characterization of a new species of Hepatozoon (Adeleorina: Hepatozoidae) from the European wild cat (Felissilvestris silvestris). Parasitology 2017;144:650-661.

14. Giannelli A, Latrofa MS, Nachum-Biala Y, Hodžić A, Greco G, Attanasi A, et al. Three different Hepatozoon species in domestic cats from southern Italy. Ticks Tick Borne Dis. 2017:8:721-4

15. Criado-Fornelio A, Buling A, Pingret $J$, Etievant M, Boucraut-Baralon C, Alongi $A$, et al. Hemoprotozoa of domestic animals in France: prevalence and molecular characterization. Vet Parasitol. 2009;159:73-6.

16. Díaz-Regañón D, Villaescusa A, Ayllón T, Rodríguez-Franco F, Baneth G, Calleja-Bueno L, et al. Molecular detection of Hepatozoon spp. and Cytauxzoon sp. in domestic and stray cats from Madrid, Spain. Parasit Vectors. 2017;10:112.

17. Vilhena H, Martínez-Díaz VL, Cardoso L, Vieira L, Altet L, Francino O, et al. Feline vector-borne pathogens in the north and centre of Portugal. Parasit Vectors. 2013;6:99.

18. Duplan F, Davies S, Filler S, Abdullah S, Keyte S, Newbury H, et al. Anaplasma phagocytophilum, Bartonella spp., Haemoplasma species and Hepatozoon spp. in ticks infesting cats: a large-scale survey. Parasit Vectors. 2018;11:201
19. Lloret A, Addie DD, Boucraut-Baralon C, Egberink H, Frymus T, GruffyddJones T, et al. Hepatozoonosis in cats: ABCD guidelines on prevention and management. J Fel Med Surg. 2015;17:642-4.

20. Hodžić A, Alić A, Duscher GG. High diversity of blood-associated parasites and bacteria in European wild cats in Bosnia and Herzegovina: a molecular study. Ticks Tick Borne Dis. 2018;9:589-93.

21. Müller N, Zimmermann V, Forster U, Bienz M, Gottstein B, Welle M. PCRbased detection of canine Leishmania infections in formalin-fixed and paraffin-embedded skin biopsies: elaboration of a protocol for quality assessment of the diagnostic amplification reaction. Vet Parasitol. 2003;14:223-9.

22. Costa JM, Pautas C, Ernault P, Foulet F, Cordonnier C, Bretagne S. Real-time PCR for diagnosis and follow-up of Toxoplasma reactivation after allogeneic stem cell transplantation using fluorescence resonance energy transfer hybridization probes. J Clin Microbiol. 2000:38:2929-32.

23. Kumar S, Stecher G, Tamura K. MEGA7: Molecular Evolutionary Genetics Analysis version 7.0 for bigger datasets. Mol Biol Evol. 2016;33:1870-4.

24. Huson DH, Bryant D. Application of phylogenetic networks in evolutionary studies. Mol Biol Evol. 2006:3:254-67.

25. Darriba D, Taboada GL, Doallo R, Posada D. JModelTest2: more models, new heuristics and high-performance computing. Nat Meth. 2012;9:772.

26. Salakij C, Salakij J, Narkkong NA, Sirinarumitr T, Pattanarangsan R. Hematologic, cytochemical, ultrastructural, and molecular findings of Hepatozoon infected flat-headed cats (Prionailurus planiceps). Vet Clin Path. 2008;7:31-41.

27. Baneth G. Perspectives on canine and feline hepatozoonosis. Vet Parasitol. 2011;181:3-11.

28. Bhusri B, Sariya L, Mongkolphan C, Suksai P, Kaewchot S, Changbunjong T. Molecular characterization of Hepatozoon felis in Rhipicephalus sanguineus ticks infested on captive lions (Panthera leo). J Parasitol. 2017:41:903-7.

29. Beaufils JP, Martin-Granel J, Jumelle P. Hepatozoon spp. parasitemia and feline leukemia virus infection in two cats. Fel Pract. 1998;26:10-3.

\section{Ready to submit your research? Choose BMC and benefit from:}

- fast, convenient online submission

- thorough peer review by experienced researchers in your field

- rapid publication on acceptance

- support for research data, including large and complex data types

- gold Open Access which fosters wider collaboration and increased citations

- maximum visibility for your research: over $100 \mathrm{M}$ website views per year

At BMC, research is always in progress.

Learn more biomedcentral.com/submissions 